\title{
Textbook Affordability Options: Assessing E-book Purchase Models for Value and Impact
}

\author{
Athena Hoeppner and Sara Duff \\ University of Central Florida, USA
}

\section{Introduction: The Growing Momentum of Textbook Affordability Efforts}

Textbook affordability (TA) is gaining momentum in academia. University libraries are well positioned to leverage their online books acquisitions to initiate and support TA efforts. However, library e-books are acquired with a variety of purchase models on different platforms with differing digital rights management (DRM) restrictions, simultaneous user (SU) limits, and user interfaces. Currently, libraries make best guesses about best practices for e-book acquisitions for books that might be used as textbooks. This paper describes efforts by the University of Central Florida (UCF) Libraries' acquisitions department to establish quantitative and qualitative data to inform library e-book acquisitions in support of TA efforts.

For years, the standard policy in the UCF acquisitions department prohibited buying textbooks. UCF has over 68,000 students, 101 bachelor's, 88 master's, and 29 research doctorates. ${ }^{1}$ Our budget cannot sustain the cost of purchasing print or single-use online textbooks in quantities to support demand. We determined that we could better support teaching and learning missions by putting limited funds towards non-textbook material. However, several factors prompted us to reconsider our textbook policy.

First, our e-book collection has grown to considerable size and contains many titles suitable for use as textbooks with unlimited simultaneous users. Second, UCF is large, with approximately 68,000 students enrolled, and is very active in online learning, with $38 \%$ of the credit hours coming from online courses. Because they can support online and distributed use, and multiple simultaneous use, e-books have the potential to be a good fit for supporting TA. Finally, Section 1004.085 of the Florida Statutes ${ }^{2}$ and Rule 6A$14.092^{3}$ both pushed colleges and universities to make college more affordable to their students, and specifically included language about textbook affordability. These mandates were, of course, unfunded, so the library had to be strategic and creative about supporting TA efforts.

\section{Previous Textbook Affordability and E-book Projects}

The interest in textbook affordability spanned many library departments, inspiring projects and collaborations in many units, including Public Services, Scholarly Communications, the Center for Distributed Learning, and Acquisitions. The focus for Acquisitions has been on using library-acquired books to reduce textbook expenses for students.

In 2016, we were granted access to the bookstore's list of assigned textbooks for the first time. We identified assigned titles that were already owned as e-books with favorable digital rights models (DRM). "Favorable," in this case, meant unlimited simultaneous usage (SU) or nonlinear lending, and the ability to download either the entire book, or chapters. We calculated a potential savings to students by multiplying the bookstore's list price per book with the enrollment for the course using the textbook and multiplying the result by three-an estimate of the number of semesters the book would be used. The total potential savings exceeded $\$ 800,000$ over three semesters. We calculated a return on investment (ROI) by dividing the total potential savings by the sum of the library's spend on the identified books. 
Figure 1. Acquisitions TA projects timeline

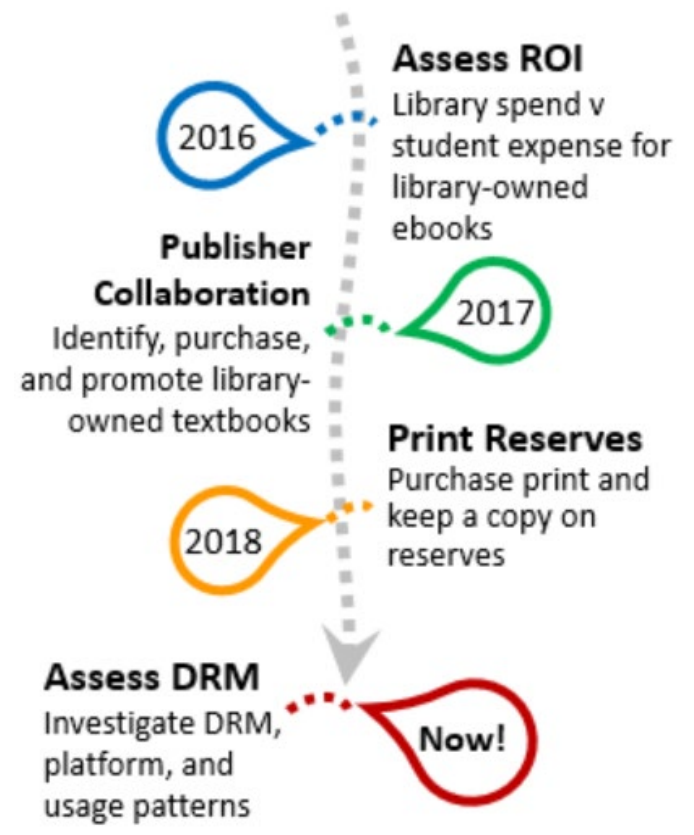

The results of the initial project were very encouraging but flawed. The potential savings calculation presumed that every enrolled student opted to use the library's online version of the book, and that they would have otherwise purchased the book at full price, and that the book would be assigned with the same level of enrollment for three semesters. We had no data on whether the faculty or the students knew about the library's e-book (though usage data for many of the identified books was significantly higher than the average).

In 2017, we collaborated with Taylor \& Francis (T\&F) in a TA effort. The library had recently joined a consortia-wide evidenced based acquisitions (EBA) plan for T\&F and had also proactively identified and purchased T\&F e-books that matched assigned textbooks. The T\&F e-books came with perpetual ownership, unlimited usage, and full book downloads. T\&F offered to monitor incoming textbook inquiries from UCF faculty, to check whether the book was either already owned or could be acquired as an e-book by UCF. If the e-book was not yet owned, UCF purchased a copy of the identified textbook. T\&F sent custom emails to the inquiring faculty to encourage them to use the library-purchased version, complete with an image of the book cover, a link which incorporated the UCF library EZproxy, and instructions on how to post the link into our Learning Management System (LMS).

Faculty were asked to fill out a survey about their use of the e-book and to share a survey with their students. The effort proved to be much more labor intensive than anticipated. Many of the faculty-supplied emails were not UCF email addresses, and the supplied course information sometimes did not align with currently offered courses. The process was far more labor intensive and time consuming than anticipated and did not result in the faculty engagement nor ROI that we had hoped for.

UCF Libraries is involved in many other TA and open education resources (OER) efforts and collaborations in addition to the two e-book projects described above. For example, the UCF Libraries was awarded a grant to supply print textbooks for selected courses via print reserves in 2018. The projects relating to print and OER benefit students and address textbook affordability in significant ways but fall outside of the scope of this paper. 
Research Questions: E-book Acquisitions Models for Supporting Textbook Affordability We learned several things from the prior projects described above and uncovered many new questions. Particularly relevant to e-book acquisitions, we needed to find out which of our many options for acquiring e-books could support use as a course textbook. We wanted data to address some very practical questions related to our purchase and e-book DRM models:

- Are DRM-free and unlimited user models worth an extra cost?

- Should we prefer publisher-hosted versus aggregator-hosted e-books?

- What is the tipping point for nonlinear being a viable model for online courses?

- Which subjects yield the best ROI or usage?

\section{UCF's E-book Purchase Models}

The library has acquired e-books in a wide variety of methods. We have participated in several consortial ebook purchases over the years, with different parameters for number of copies available, shared and unshared copy pools, and various DRM models. We have purchased several e-book collections from aggregators, including several of the Solinet NetLibrary Shared Collections which date back to the early days of e-book collections. We continually purchase publisher collections, such as Springer e-books and Oxford Scholarship Online. Some of the collections are purchased consistently, year after year. Others have gaps and skipped years. We participated in several DDA (demand-driven acquisitions) and EBA (evidence-based acquisitions) programs, both on our own and as part of a consortia. Of course, we also purchase many ebooks title-by-title as firm order requests from our subject librarians.

\section{Usage Limits and DRM Models}

Just as we have many business and purchasing arrangements, the library's e-book collection incorporates a variety of usage limits and DRM models. For the project, we distinguished three main usage/DRM models:

Unlimited Users (UU): There is no limitation on the number of simultaneous users (SU) for these titles, and no limitation on the number of times users can access these titles. This is the perfect model for textbooks, even if the title is not completely DRM-free. Typically, titles on publisher platforms (such as Taylor \& Francis, Springer, etc.) will be unlimited and DRM-free, which means that students can download a PDF copy of the entire book. Unlimited titles on aggregators, like ProQuest Ebook Central and EBSCO, may or may not be DRM free, so there may be limitations on the number of pages a user can print or download.

Nonlinear/Concurrent: ProQuest uses the term "nonlinear" and EBSCO uses the term "concurrent," but they mean essentially the same thing. One of these e-books will have a limited number of uses per year, and the uses typically refresh on the anniversary of purchase. A typical nonlinear e-book will have 325 uses per year, though some will have 200. The number of uses remaining is not viewable from the user side. It is important to note that a nonlinear use is defined differently from a COUNTER use. In ProQuest, a nonlinear use is not assessed unless the e-book has been read for longer than five minutes, or content has been downloaded or printed. Anything below five minutes is counted as a "free view." UCF did not have any EBSCO concurrent e-books assigned as textbooks, but we did have several nonlinear e-books used as texts. In most cases, the nonlinear model was sufficient for these courses. However, it is important to monitor usage and be willing to purchase another copy or upgrade to unlimited if the uses get low.

Limited User Copies: Many e-books are not available as unlimited or nonlinear. Instead, these e-books may state a specific number of simultaneous users, such as one, three, six, or any other number. There is no limit on the number of times this book can be used, but it can only be used by that number of people at the same time. UCF has many titles with a specific number of users listed, and many of those came from consortial deals. Oftentimes a vendor acquires another platform and will migrate a package over (say, NetLibrary moving to EBSCO) that was purchased by a consortia or other group. Consortial deals, particularly legacy deals made in the early days of e-books, often stipulated that the group purchase a specific number of "copies" that translated into a number of SUs, either as a shared pool or with one SU designated per participating library. As a result of our consortia participation, we have thousands of titles that have one 
user, six users, twelve users, or some other number. For example, we have many e-books that say "12 copies" that are a result of a consortial DDA in MyiLibrary. Though these e-books are now in ProQuest, the original terms of the group deal were that each time an e-book was triggered for purchase by the group, a copy was purchased for each library. So, though UCF technically only owns one single-user copy, we have access to all 12 copies purchased by the consortia. This can obviously be confusing and getting locked out of an e-book can be frustrating for users. All students in a course frequently need to access the e-book in the same time frame when they have assignments due, so our starting assumption is that the limited-users model is not suitable for textbooks.

Table 1: Summary of E-book Platforms and DRM/Usage Models at UCF

\begin{tabular}{|l|l|l|l|l|l|l|l|}
\hline Platform & DDA & EBS & $\begin{array}{l}\text { Title / } \\
\text { Firm } \\
\text { SU }\end{array}$ & $\begin{array}{l}\text { Non- } \\
\text { linear }\end{array}$ & $\begin{array}{l}\mathbf{1 2} \\
\text { Copies }\end{array}$ & UU \\
\hline ACLS & & & & & & & $\checkmark$ \\
\hline Cambridge & & $\checkmark \square$ & $\checkmark \square$ & & & & $\checkmark \square$ \\
\hline EBSCO & & & $\checkmark \square$ & $\checkmark \square$ & $\checkmark \square$ & & $\checkmark$ \\
\hline Elsevier & & & $\checkmark \square$ & & & & $\checkmark$ \\
\hline Oxford & & & & & & & $\checkmark$ \\
\hline ProQuest & $\checkmark \square$ & & $\checkmark \square$ & $\checkmark \square$ & $\checkmark \square$ & $\checkmark \square$ & $\checkmark \square$ \\
\hline SPIE & & & & & & & $\checkmark$ \\
\hline Springer & & & & & & & $\checkmark$ \\
\hline T\&F & & $\checkmark \square$ & & & & & $\checkmark$ \\
\hline Wiley & & & $\checkmark \square$ & & & & $\checkmark$ \\
\hline
\end{tabular}

\section{Methodology: Data Gathering, Cleanup, Matching}

Our project required us to gather data from disparate sources. We obtained course data, including enrollment, sections, and faculty names, from the university's Institutional Knowledge Management (IKM) unit. Acquisitions records and GOBI provided e-book titles, purchase price (if available), collections and packages, host platforms, purchase model, and the DRM for each e-book. Usage data came from COUNTER BR1 and BR2 reports for the fall 2018 semester from August $1^{\text {st }}$ through October $31^{\text {st }}$, and additional usage details came from special non-COUNTER reports provided by the administrative modules for e-book aggregator platforms, such as the ProQuest Ebook Central usage reports.

Finally, and crucially, we needed the list of fall 2018 textbooks. The textbook list provides vital information, including titles, ISBNs, course numbers, enrollment, and faculty names. The data is compiled and controlled by the campus bookstore. Historically, the bookstore has treated the textbook list as proprietary and secret and has not shared the information with the library. Since 2016, the library has gained limited access to parts of the list.

Matching the textbook list against our holdings was done by searching the library catalog, title by title, and recording the online versions listed in the results. Likewise, finding the purchase, SUs, and DRM information per book involved checking title by title in GOBI or other purchase records. These two steps were performed by a colleague in UCF's Center for Distributed Learning. 
The data sets we gathered were created by different units for different purposes, and, for our purposes, had many problems, such as malformed ISBNs, ISBNs for different editions or formats for the title, or missing ISBNs entirely. Some of the titles for the books were incomplete, while others had extraneous notes tacked on the end. A variety of capitalization and punctuation schemes were applied, even within the same data sets. Acquisition data, such as price and specific circumstances of the purchase, was inconsistently available. Many of these e-books were purchased in large collections with no per-title pricing on the invoice. Others were part of consortia-wide deals, with a pool of shared titles purchased at a discount. Even COUNTER 4 usage reports were problematic because some of the host platforms provide chapter level usage data (BR2Number of Successful Section Requests by Month and Title), while others provide book level data (BR1Number of Successful Title Requests by Month and Title). Very few platforms provide both COUNTER BR1 and BR2 statistics, making comparisons impossible in some cases.

Finally, we opted to scope the project by only including platforms that provide titles that would be considered "books" in the modern sense of the word, and by eliminating courses with fewer than 5 students from our list, in the likelihood that those classes had been cancelled. The resulting data would, we hope, better reflect normal UCF textbook and e-book norms and so provide a better basis for analysis and conclusions.

\section{Digging into the Data Textbooks per Platform}

After cleaning the data, we used Excel functions and manual verification to match elements across the different sources and began looking for trends. Checking the library catalog for the titles on the bookstore's list for fall 2018 textbooks identified 96 e-books in the library's collection that matched the assigned textbooks in 93 courses with five or more students enrolled. The identified e- books were hosted on ten platforms, providing a representative cross section of options including aggregator and publisher platforms, subject collection, DDA, firm orders purchases, unlimited users, nonlinear users, short-term loans, and limited user copies ranging from 1 to 12 .

Table 2: Courses and Enrollment Counts per Platform

\begin{tabular}{|l|l|l|l|l|}
\hline Platform & Courses & E-books & Course Enrollment & Potential Student Spend \\
\hline ACLS & 4 & 4 & 205 & $\$ 5,298$ \\
\hline Cambridge & 3 & 3 & 72 & $\$ 2,755$ \\
\hline EBSCO & 23 & 24 & 931 & $\$ 59,458$ \\
\hline Elsevier & 1 & 1 & 48 & $\$ 2,296$ \\
\hline ProQuest EBL & 42 & 43 & 2182 & $\$ 4,366$ \\
\hline ProQuest ebrary & 1 & 1 & 12 & $\$ 99,675$ \\
\hline SPIE & 1 & 1 & 20 & $\$ 1,680$ \\
\hline Springer & 11 & 11 & 199 & $\$ 896$ \\
\hline T\&F & 6 & 7 & 272 & $\$ 20,932$ \\
\hline Wiley & 1 & 1 & 28 & $\$ 17,840$ \\
\hline Total & 93 & 96 & 3969 & $\$ 215,196$ \\
\hline
\end{tabular}


We were surprised that most of the matched textbooks were on an aggregator platform, with 43 hosted on ProQuest and 23 on EBSCO. We had predicted that the books on platforms would match the most assigned textbooks because they are more likely to have unlimited users and because of their reputation of publishing scholarly content aligned with UCF's programs.

Table 3: E-books in UCF's Collection versus Textbooks Matched per Platform

\begin{tabular}{|l|l|l|}
\hline Platform & \% of Total E-books & \% of Textbooks \\
\hline ACLS & $2.37 \%$ & $4.17 \%$ \\
\hline Cambridge & $0.02 \%$ & $3.13 \%$ \\
\hline EBSCO & $33.18 \%$ & $25.00 \%$ \\
\hline Elsevier & $0.09 \%$ & $1.04 \%$ \\
\hline Oxford & $5.78 \%$ & $0.00 \%$ \\
\hline ProQuest & $15.40 \%$ & $45.83 \% \%$ \\
\hline SPIE & $0.15 \%$ & $1.04 \%$ \\
\hline Springer & $42.60 \%$ & $11.46 \%$ \\
\hline T\&F & $0.21 \%$ & $7.29 \%$ \\
\hline Wiley & $0.21 \%$ & $1.04 \%$ \\
\hline
\end{tabular}

Of the platforms that provide what we think of as a modern, scholarly book, ProQuest, EBSCO, and Springer host the most titles, at $15 \%, 33 \%$, and $43 \%$ respectively. Even though ProQuest only hosts $15 \%$ of UCF's ebooks on the platforms in our study, it hosts $45 \%$ of the identified textbooks.

Clearly, the number of titles on the platform does not directly translate into the percentage of matched textbooks. The method of e-book selection may be an important factor. Most of our ProQuest e-books were acquired via DDA or firm order, with either nonlinear or unlimited usage. They tend to be recent and, because they were selected title-by-title by students, faculty, and librarians, likely to be very relevant to UCF's programs of study, which may explain why ProQuest titles matched the most textbooks. Further investigation is needed to determine if the pattern continues and whether DDA and firm order books more often match textbooks on other platforms. 
Chart 1: Textbooks per DRM per Platform

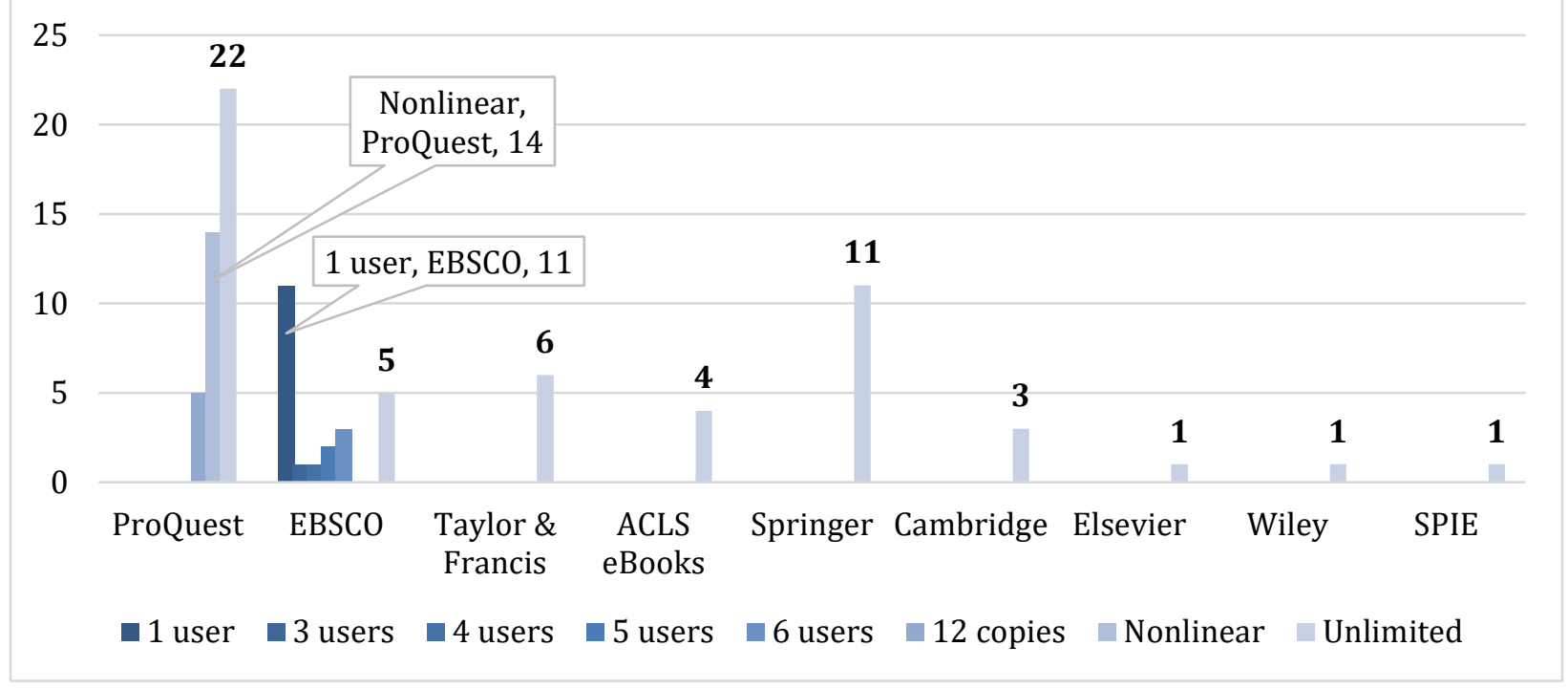

Comparatively, while EBSCO hosts nearly twice as many e-books as ProQuest, they were overwhelmingly acquired as part of the legacy NetLibrary Shared Collections. Most of the collection is more than 10 years old, the individual titles were not specifically selected, and most permit only one SU. The more recent EBSCO additions have been made through firm orders, and librarians may select whichever SU model they think is appropriate. The size of the EBSCO collection, combined with the mixture of publication dates and SU models may explain why EBSCO books matched at a higher rate than most platforms, but at a lower percentage than we might have guessed based on the collection size.

For publisher platforms, UCF purchases subject collections, with only a smattering of firm orders. All the books have unlimited SUs. Springer is notable as our longest-running and largest publisher-hosted collection. We have purchased most English-language Springer e-books from 2005 to present, making it our largest single provider of modern e-books and we have encouraged faculty to consider using the titles as ebooks. Springer e-books make up a whopping $42 \%$ of UCF's e-books on the platforms listed in Table 3.

Eleven percent of the identified textbooks were Springer e-books-higher than the other publisher packages, but not in proportion to the size of the collection.

\section{COUNTER Usage per Platform}

We predicted that students would discover and use the library's online copy of the assigned textbooks-after all, "Does the library have my textbook?" is the most common question asked at the reference desk during the first two weeks of the semester. All other factors being equal, we would expect usage per textbook would correlate closely with course enrollment. Of course, the factors are not equal, and the usage patterns turned out to be far from straightforward.

Neither the number of identified textbooks per platform, nor enrollments in the courses, predicted usage. For example, the ACLS textbooks for four courses with 205 students had no usage during fall 2018. EBSCO matched twenty-three courses with 931 students enrolled, but only one of the books was used, with a paltry 15 section uses reported on BR2. The forty-three textbooks on ProQuest, on the other hand, were used over 47,000 times during the semester.

Table 3: Courses, Enrollment, and Usage per Platform

\begin{tabular}{|l|l|l|l|l|l|l|}
\hline Platform & Courses & Enrollment & BR1 & BR2 & \% BR1 Use & \% BR2 Use \\
\hline ACLS & 4 & 205 & - & - & $0 \%$ & $0 \%$ \\
\hline
\end{tabular}




\begin{tabular}{|l|l|l|l|l|l|l|}
\hline Platform & Courses & Enrollment & BR1 & BR2 & \% BR1 Use & \% BR2 Use \\
\hline Cambridge & 3 & 72 & - & 8 & $0 \%$ & $0 \%$ \\
\hline EBSCO & 23 & 931 & - & 15 & $0 \%$ & $0 \%$ \\
\hline Elsevier & 1 & 48 & - & 315 & $0 \%$ & $1 \%$ \\
\hline ProQuest EBL & 42 & 2182 & 362 & 47,010 & $58 \%$ & $95 \%$ \\
\hline ProQuest ebrary & 1 & 12 & - & 11 & $0 \%$ & $0 \%$ \\
\hline SPIE & 1 & 20 & 5 & - & $1 \%$ & $0 \%$ \\
\hline Springer & 11 & 199 & 1 & 1,856 & $0 \%$ & $4 \%$ \\
\hline T\&F & 6 & 272 & 253 & 51 & $41 \%$ & $0 \%$ \\
\hline Wiley & 1 & 28 & - & - & $0 \%$ & $0 \%$ \\
\hline Total & 93 & 3969 & 621 & 49,266 & $100 \%$ & $100 \%$ \\
\hline
\end{tabular}

The BR1 and BR2 usage patterns were quite different, which bears some explanation. BR1 usage reports how often an entire book is used (displayed or downloaded). BR2 reports how often a section (i.e., a chapter) of a book is used. Most platforms support, or emphasize, chapter use, while a few emphasize downloading the entire book. When a student reads a book on a platform that emphasizes chapter-level use, a BR2 usage count is generated for each chapter the student accesses, every time they access it. If the student accesses the same book on a platform that emphasizes downloading the entire book, and the student uses their alreadydownloaded copy for the entire semester, the BR1 report will count only one use of the title. As a result, BR2 reports tend to have much higher totals than BR1.

The UU books on ProQuest generated the most usage. However, the nonlinear and 12-SU e-books had significant usage, too. The one EBSCO book with 15 BR2 uses had 6-SU. All the remaining BR2 use was UU on the publisher platforms. 
Chart 2: BR2 Usage per DRM Model per Platform

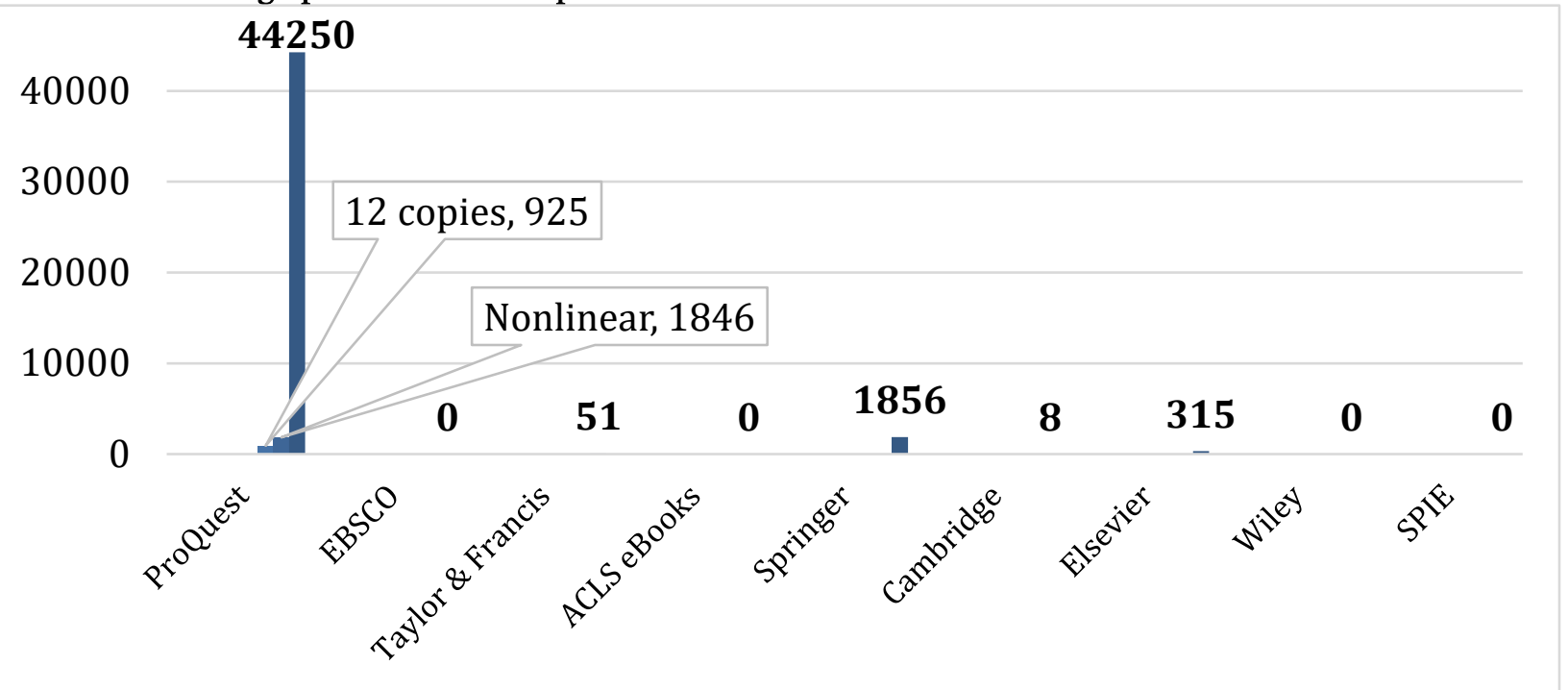

Only Taylor \& Francis and ProQuest provided BR1 reports. ProQuest, once again, had the most usage. We also saw a significant use on Taylor \& Francis.

Chart 3: BR1 Usage per DRM Model per Platform

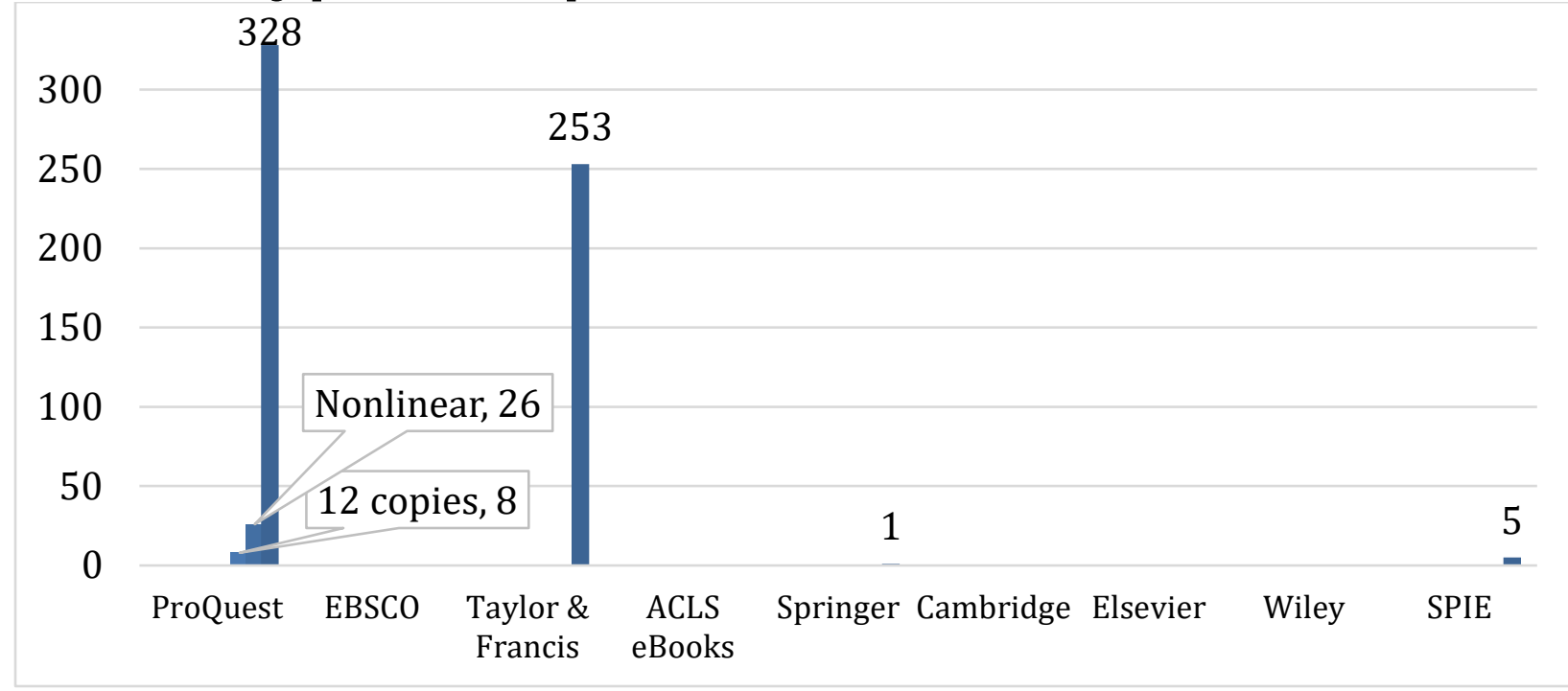

\section{Usage per Student}

Dividing the total use of the textbooks on a platform by the number of enrolled students in the associated courses gives a use per enrolled student ratio. The ratio does not let us know whether the students in the specific courses we identified were the people using the book, but a higher use per student ratio does indicate that the enrolled students could feasibly drive the usage. According to fall 2018 BR2 data, ProQuest's hosted textbooks were used, on average, 21 times per student. Springer and Elsevier also had use per enrolled student ratios that imply that every enrolled student might have used the library's online copy of the textbook. 


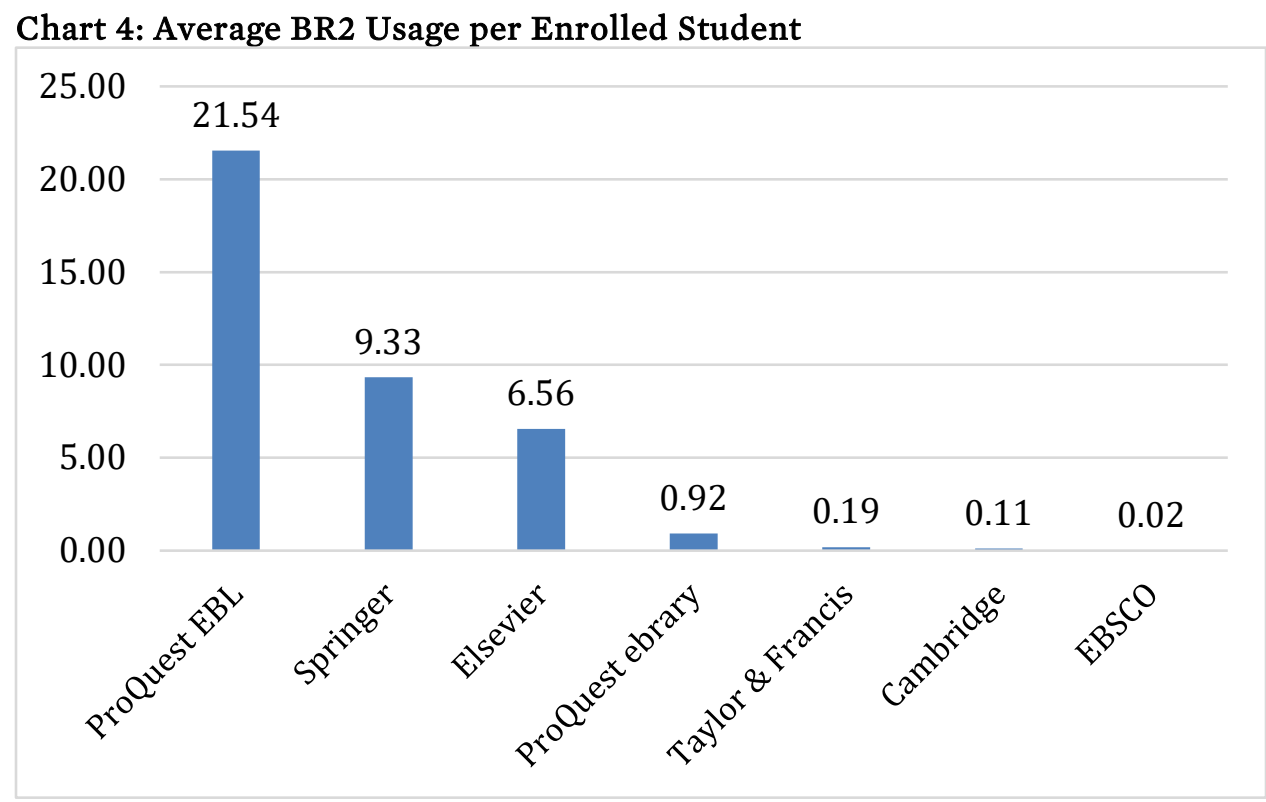

Use on ACLS, Cambridge, EBSCO, SPIE, and Wiley was low enough to imply that the enrolled students did not attempt to use the online book. Perhaps students did not know about the library's online copy, or knew about the copy, but found it unacceptable for some reason, such as an unfriendly user interface, discouragement by faculty, or need for offline access. We have no data to strengthen or debunk our speculations.

BR1 data shows Taylor \& Francis-hosted textbooks were used approximately one time per student enrolled in the corresponding courses.

\section{Chart 2: Average BR1 Usage per Enrolled Student}

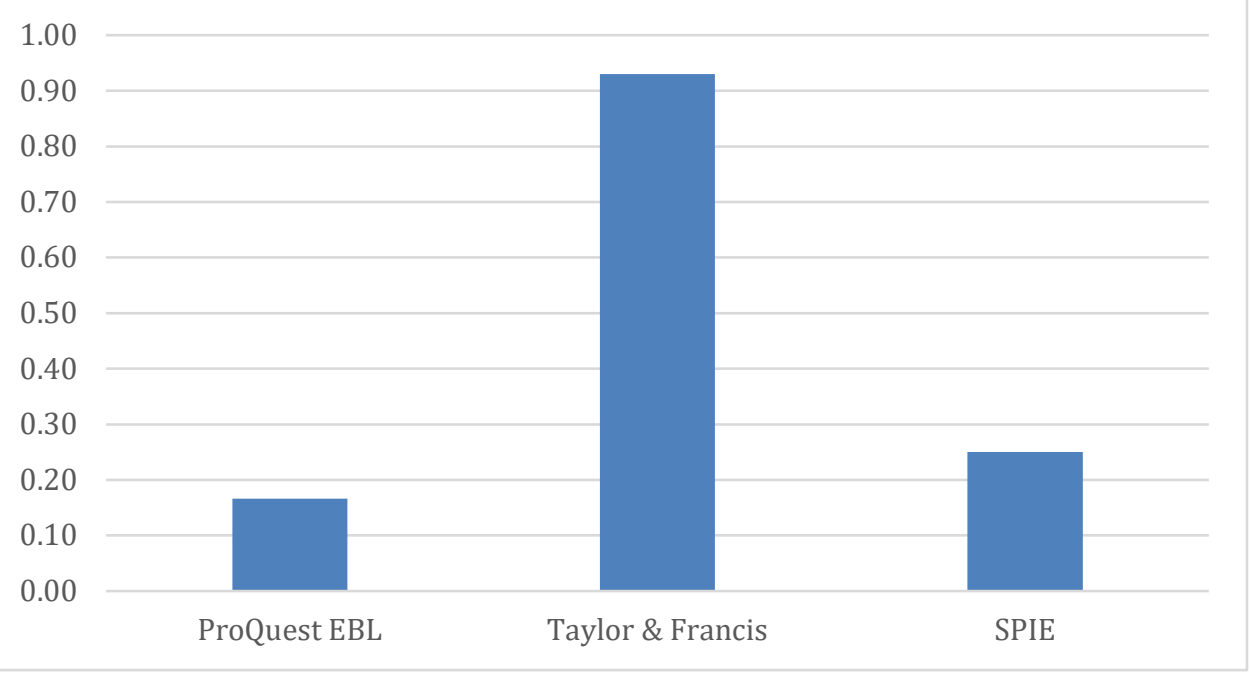

\section{Nonlinear Textbook Case Study}

To determine the tipping point for nonlinear e-books as textbooks, we examined the use of a specific nonlinear title by a course with enrollment large enough to cause usage to exceed the usage allotment. "Nonlinear" is a ProQuest model wherein the library gets a fixed number of uses, typically 325, for a title per year. The uses can all be simultaneous, so several students can access chapters and assigned readings at once. The usage pool refreshes on the anniversary of the purchase of the e-book. If the usage-pool is used up, then 
access to the book is blocked for the remainder of the year, or, if the book is still available for nonlinear purchase, the library can pay for additional "copies," essentially doubling the number of allowed uses per year.

UCF purchased the book The Design of Everyday Things by Don Norman on the ProQuest platform with the nonlinear model with 325 uses per year. The title is the assigned textbook for Fundamentals of Interactive Design, a course taught in the fall and spring semesters, with enrollment ranging from 249 to 446 students a semester. Usage of the library's nonlinear copy of the title has been strong every semester the course is taught. During the spring 2018 semester, the nonlinear limit of 325 was reached. The usage pool refreshed in the summer, so there were enough remaining for the fall semester, but we predict that we will run out again during spring 2019.

Table 5: Usage and Enrollment Comparison per Semester

\begin{tabular}{|l|l|l|}
\hline Semester & Usage & Enrollment \\
\hline Fall 2018 & 129 & 390 \\
\hline Summer 2018 & 0 & 0 \\
\hline Spring 2018 & 263 & 249 \\
\hline Fall 2017 & 45 & 446 \\
\hline Summer 2017 & 1 & 0 \\
\hline Spring 2017 & 215 & 345 \\
\hline
\end{tabular}

Interestingly, usage of the title has been strongest during spring semesters, even though enrollment has been higher in the fall. We are not sure what is causing the spring usage bump. Different faculty members teach the course each semester. Perhaps some of the faculty promote the e-book, while others do not, or some may emphasize reading assignments more than others.

The rest of the nonlinear textbooks, however, have not been as heavily used. Of the thirteen nonlinear textbooks we identified, only four had ten or more nonlinear uses. Note that nonlinear uses are not the same as COUNTER usage. A nonlinear use is assessed when an e-book is used for longer than five minutes at a time, or if the reader has saved a PDF or printed from the book. COUNTER usage is tallied for any access of the full text of the book, no matter how short. Many of the titles had robust COUNTER usage for the fall 2018 semester, even though a small number of nonlinear loans were counted, leaving a large pool of nonlinear uses available.

Table 6: Usage, Loans, and Enrollment for Nonlinear Textbooks

\begin{tabular}{|l|l|l|l|l|l|l|}
\hline Title & $\begin{array}{l}\text { BR2 } \\
\text { Fall 2018 }\end{array}$ & $\begin{array}{l}\text { NL } \\
\text { Renewal } \\
\text { Date }\end{array}$ & $\begin{array}{l}\text { NL Loans } \\
\text { Left }\end{array}$ & $\begin{array}{l}\text { Loans } \\
\text { used }\end{array}$ & $\begin{array}{l}\text { Upgrade } \\
\text { Cost }\end{array}$ & $\begin{array}{l}\text { Fall 2018 } \\
\text { Enrolled }\end{array}$ \\
\hline Abandoned in the Heartland & 174 & Sep 19 & 321 & 4 & $\$ 0$ & 8 \\
\hline Black sexual politics & 77 & Jun 19 & 325 & 0 & $\$ 26$ & 25 \\
\hline Business model generation & 105 & Dec 18 & 315 & 10 & $\$ 26$ & 181 \\
\hline Directing for animation & 0 & May 19 & 324 & 1 & n/a & 8 \\
\hline
\end{tabular}




\begin{tabular}{|l|l|l|l|l|l|l|}
\hline Title & $\begin{array}{l}\text { BR2 } \\
\text { Fall 2018 }\end{array}$ & $\begin{array}{l}\text { NL } \\
\text { Renewal } \\
\text { Date }\end{array}$ & $\begin{array}{l}\text { NL Loans } \\
\text { Left }\end{array}$ & $\begin{array}{l}\text { Loans } \\
\text { used }\end{array}$ & $\begin{array}{l}\text { Upgrade } \\
\text { Cost }\end{array}$ & $\begin{array}{l}\text { Fall 2018 } \\
\text { Enrolled }\end{array}$ \\
\hline $\begin{array}{l}\text { Examination of orthopedic \& } \\
\text { athletic injuries }\end{array}$ & 646 & Mar 19 & 295 & 30 & $\$ 48$ & 40 \\
\hline Fundamental mechanics of fluids & 265 & Jan 19 & 296 & 29 & $\$ 88$ & 42 \\
\hline Holy legionary youth & 3 & Dec 19 & 324 & 1 & $\$ 110$ & 12 \\
\hline Information architecture & 105 & Aug 19 & 325 & 0 & n/a & 56 \\
\hline $\begin{array}{l}\text { Jonas' introduction to the U.S. } \\
\text { health care system }\end{array}$ & 0 & Apr 19 & 325 & 0 & $\$ 129$ & 10 \\
\hline Quality and safety in nursing & 0 & Dec 18 & 325 & 0 & n/a & 6 \\
\hline $\begin{array}{l}\text { Social work practice with groups, } \\
\text { communities, and organizations }\end{array}$ & 7 & Feb 19 & 195 & 5 & $\$ 18$ & 67 \\
\hline $\begin{array}{l}\text { Statistics for health care } \\
\text { management and administration } \\
\text { working with Excel }\end{array}$ & 349 & Mar 19 & 83 & 117 & $\$ 28$ & 11 \\
\hline Unholy war & 10 & Jun 19 & 323 & 2 & $\$ 8$ & 43 \\
\hline
\end{tabular}

There are many variables with nonlinear textbooks, but overall, we were surprised to see how many nonlinear loans remained at the end of the semester. Much of the COUNTER usage was counted as "free views" in ProQuest's system, meaning that a lot of textbook usage seems to be quick views to look something up.

\section{Concluding Thoughts}

A few findings and trends stood out in our data and analysis. UCF's overall e-book usage is trending upward, as is the number of e-books in the collection. Use of the e-books for all e-books and for textbooks, with usage heaviest during fall semesters. Chapter-level usage, reported in COUNTER BR2 data, is robust for all UCF ebooks. BR1 usage is relatively lower.

The number of e-books that matched fall 2018 textbooks is relatively small considering the number of ebooks in UCF's collection and the number of courses offered. That said, if the approximately 3,900 students in the courses opted to use the library e-book, the potential savings to students is over $\$ 215,000$ for the semester.

As we expected, unlimited uses books were most often matched to assigned textbooks and had the highest usage. However, UU books on publisher platforms had uneven usage and many publisher platforms had no use of the textbooks whatsoever. Use of T\&F e-books was low, due in part to the platform's preference for full book downloads. In addition, we discovered that T\&F had stopped recognizing our proxy sometime in November, preventing all use of their e-books from off-campus. The problem lasted for at least one week, perhaps longer, and may have had major impact on our usage statistics. However, given that we specifically sought out and purchased $\mathrm{T} \& \mathrm{~F}$ textbooks in a prior project and identified several titles that were marketed to faculty, we predicted high use for all the matched T\&F e-books, and it did not materialize. Clearly, DRMfree and unlimited users are a plus, but do not ensure that the library's copy of a textbook will be found and used. 
In addition to unlimited use, nonlinear proved to be a viable approach, but requires acquisitions employees to monitor the loans, and periodically check to ensure that they can either upgrade or purchase a second copy if required. From this project, it appears that the other DRM models do not work well for textbooks. None of the UCF library's one to six user titles had any usage. The e-books were either dismissed as a poor option, were not discovered by faculty and students, or there were barriers to finding and using these titles.

The most surprising finding was the exceptionally strong showing of ProQuest-hosted textbooks. The biggest difference between ProQuest, EBSCO, and the many publisher platforms is the method we used to acquire most of the books. ProQuest is the platform for our largest and longest-running DDA deal. Additional studies are warranted to determine if the DDA model is truly a good approach to support TA, and how it can be best leveraged. Several additional factors likely come into play, such as the course level and program, cost of the textbook, and preferences of the faculty and students. Further investigation is needed to determine influence of the factors and establish patterns.

\section{Unknowns and Further Exploration}

We do not yet know how many faculty members knew about the library's copies of the textbooks or promoted the e-books to their students. We do not know if students found them on their own, through library outreach efforts, or if most students were not aware that the library had an online copy of their textbook at all. For students that did know about the library's e-book, we do not know whether they felt the e-book version was adequate, or if they were frustrated by DRM restrictions or the usability of platforms.

In fact, we do not know if the usage was generated by the students enrolled in the identified courses. It could be that the usage is driven by only a handful of students in each course and by other UCF students.

We plan to continue our investigation and gather more information, particularly relating to student interest or adoption of library e-books. We have prepared a very quick two-question survey that we will target to classes with assigned textbooks that have library e-book counterparts. The survey will ask students to rate their satisfaction with the library version and the bookstore version of the textbook. The results will let us determine how many students used the library e-book and how many obtained a copy from the bookstore. The new data will enable us to estimate student spend on selected textbooks and the relationship between students using the library text and COUNTER usage for that e-book. The planned survey is currently awaiting IRB approval. We anticipate sending it out late in spring and follow up with another paper or presentation in 2020.

-Copyright 2019 Athena Hoeppner and Sara Duff

Athena Hoeppner

Discovery Services Librarian

athena@ucf.edu

Sara Duff

Acquisitions \& Collection Assessment Librarian

Sara.Duff@ucf.edu

\section{Endnotes}

1. "UCF Facts 2018-19," University of Central Florida,, accessed January 21, 2019, https://www.ucf.edu/about-ucf/facts/.

2. Textbook and Instructional Materials Affordability, Fla. Stat. Education Code. Public Postsecondary Education, 8 1004.085 (2018), http://www.leg.state.fl.us/statutes/index.cfm?App_mode=Display_Statute\&URL=10001099/1004/Sections/1004.085.html.

3. Textbook Affordability, Fla. Admin. Code 6A-14.092 (2017), https://www.flrules.org/gateway/ruleno.asp?id=6A-14.092\&PDate=8/28/2017\&Section=3. 